\title{
What will be the effects of the new European environmental legislation on innovation in the electronics sector?
}

\author{
S. Giesecke \& T. Tötzer \\ Austrian Research Centers, Austria
}

\begin{abstract}
The Europe-wide legislation on electronics and environment (WEEE, RoHs) is not only an indicator of a more environmentally friendly electronics industry. At the same time it presents a challenge to policy makers for the coordination of multilevel governance: Legislation on the EU level is directly affecting the national level, the regional level, and the local communities and vice versa. To this date, the effects WEEE, RoHs etc. have or will have on innovation (more precisely on innovation policy) are still widely unexplored. For example, the new environmental legislation measures call for a reduction of hazardous substances and the avoidance of waste at the point of design. This calls for a new organisation of the innovation process in the electronics industry. Since the electronics sector is an important pillar of the economy in many European countries, innovation policy on the national level will (have to) react to the new requirements in order to keep their economy competitive. To this date, however, it seems that most countries undertake very little efforts - aside from implementing EU regulations - in order to trigger innovation in the green electronics sector.

Keywords: WEEE, RoHS, research and technology policy, environmental policy, innovation.
\end{abstract}

\section{Introduction}

The Europe-wide legislation on electronics and environment is not only an indicator of a more environmentally friendly electronics industry. At the same time it presents a challenge to policy makers for the coordination of multilevel governance: Legislation on the EU level is directly affecting the national level, 
the regional level, and the local communities and vice versa. To this date, what effects WEEE, RoHS, etc. have or will have

- on innovation in firms and

- on innovation policy

is still widely unexplored. For example, the new environmental legislation measures call for a reduction of hazardous substances and the avoidance of waste already at the point of design. This calls for a new organisation of the innovation process in the electronics industry. Since the electronics sector is an important pillar of the economy in many European countries innovation policy on the national level will (have to) react to the new requirements in order to keep their economy competitive.

Our paper is work in progress as our research project just started this year. In our work, we are going to explore the effects of the new environmental legislation on the national research, technology, and innovation policies within the EU. Meanwhile, all states have already reacted and implemented the directives on the national level. Some states have undertaken efforts to establish programmes for supporting innovations in the electronics sectors that are environmentally friendly. We have to note that next to legal measures the governments have several instruments for an active research, technology, and innovation policy. They can provide funds for support programmes, they can provide a certain infrastructure, they can act as networkers, bringing all the relevant players together, and they can provide all information necessary for initiating certain actions. Besides the legal and information measures, most states have not yet reacted or tried to integrate the new challenges into their established funding programmes. In our presentation, we will give examples for each type of strategy and we will try to categorize and interpret our findings.

\section{The Aims of WEEE and RoHs}

The production of electrical and electronic equipment is one of the fastest growing domains of manufacturing industry in the Western world (EC [3]). A study ordered by the European Commission illustrates that in 1998, 6 million tonnes of waste electrical and electronic equipment were generated $(4 \%$ of the municipal waste stream) and that the volume of WEEE is expected to increase by at least 3-5\% per annum (AEA Technology [2]). In addition to the increasing amount of waste, WEEE consists of a complex mixture of different materials and components which often contain hazardous substances. This poses a significant obstacle to environmentally friendly disposal or recycling. These findings led to the adoption of two EU directives: the WEEE (Directive 2002/96/EC on Waste Electrical and Electronic Equipment) directive on electrical and electronic waste and the RoHS (Directive 2002/95/EC on the Restriction of the Use of Certain Hazardous Substances in Electrical and Electronic Equipment) directive on hazardous substances in electrical and electronic equipment. The RoHS and WEEE directives ought to supplement each other: the RoHS directive seeks to 
reduce waste right at the source and thus aims to avoid hazardous waste to begin with. The WEEE directive focuses on the end-of-life of EEEs and follows the principle of recycling; if waste already exists it is to be reintegrated into the cycle of matter. A third directive (EuP - The EuP directive was adopted as framework directive 2005/32/EC on the eco-design of Energy-using Products (EuP) and is to be implemented nationally by August 2007) has been adopted by the European Parliament in 2005 and is currently in discussion and preparation on the state level. The EuP directive does not introduce directly binding requirements, but sets a framework for eco-design requirements for energy-using products that has to be translated into measures to be implemented by the states of the European Union. These three EU directives are said to show the largest effects on the European electronics industry ever and will lead to massive changes (EBV Elektronik [4]).

However, the new EU directives not only have a significant impact on the electrical and electronics industry. Several stakeholders from national to local scale are affected and have to contribute if the directives are to be implemented successfully. First, the EU directives have to be transposed into national law. In many cases, such as the WEEE directive, the general requirements of the EU directive have to be concretised by the authorities in the member states. In Austria, the Federal Ministry of Agriculture, Forestry, Environment and Water Management was in charge for transposing the WEEE and RoHS directive into Austrian law. This indicates that the WEEE and RoHS directives are meant to be environmental regulations. However, the agreement of the Ministry of Economics and Labour was required. In any case, an intensive exchange between the ministries and with representatives from industry was necessary. Finally the legal requirements have to be implemented by firms and on a local scale by local collection facilities. Besides, the user of EEEs has to be considered as an important actor in the life cycle of a product. He decides for and buys the product and has to dispose of it appropriately for it to be treated as required by the EU directives.

\section{Directives and their effects on innovation: The Austrian experience}

In our research project we intend to explore which effects WEEE, RoHS, etc. have or will have on innovation and on innovation policy. In this context, we understand innovation as any newly developed or improved products, technologies, and services brought to market. First, we will shortly discuss whether legislation is basically believed to be a stimulus for innovations. Second, the Austrian experience on the effects of WEEE and RoHS on innovations will be presented.

WEEE and RoHS are environmentally motivated regulations. These two directives aim to improve the environmentally friendliness of EEE. There are two kinds of stimuli on (eco-)innovations - internal and external - and regulations are external ones. Although studies illustrate that internal stimuli such as potential market opportunities and competitive advantage are stronger 
driving forces for eco-oriented innovation than external stimuli, among the external stimuli legislation is one of the most influential ones (Tötzer and ÖmerRieder, [14], van Hemel and Cramer, [5]).

Generally, market pull and technology push are driving forces for innovation. Eco-innovations and sustainable innovations commonly need additional political support (regulatory push), because the double externality problem reduces the incentives for firms to invest in environmental innovations (Rennings et al., [10]). From an economic perspective, market failure explains the high importance of political measures such as regulations, incentives, funding, and providing an appropriate framework as key determinants for eco-innovative behaviour of firms (Lehr and Löbbe, [9]; Rennings, [11]; Hübner et al., [6]). In particular, environmental regulations are believed to be key drivers for environmental and sustainable innovations (Rennings et al., [10]). Some authors note that the prospect of regulation might be an even stronger driver to stimulate technological innovation in the forefront than the actual implementation of regulation (Jänicke, [7]; SRU, [13]; Kemp, [8]).

When exploring impacts of a concrete legislation on innovations, one has to probe deeper and analyse its historical development and effects comprehensively. The WEEE and RoHS directives affect various stakeholders in very different ways. When analysing the effects, SME-suppliers, large companies, and importing companies have to be distinguished.

Large companies, for the most part, were able to manage the change towards the new directives in time. They did have enough resources to gather the necessary information and to develop strategies for the implementation of the changes required. If necessary, they hired additional personnel to help readjust production and organisation. We can confirm the findings by other authors that the mere announcement of regulatory change functions as an innovative impulse. At first, this is more so, though, at organisational level than at product level. Whether these impulses can really be transferred into eco-innovative products that are profitable for the company depends on the de facto implementation of the regulations announced. If the innovation is successful at one company it will also have some impact on suppliers as well as competitors.

Small and medium enterprises (SMEs) usually are quite late in learning about new regulations such as WEEE and RoHS. Much information would be available, but SMEs usually do not have the resources to keep in touch with the development of a new regulation over several years. On the contrary, they are often overwhelmed by too much information and would need specific consultation on the consequences of a regulation for their individual firm. In addition, they often cannot afford taking the risk of being a first mover. In many cases, their major driving force for adaptation is the client (e.g. Original Equipment Manufacturers) who orders products that have to conform to the new regulations. In any case, in contrast to the bigger companies, they do not have the resources to engage in extensive research on the changes to come or to develop new strategies. Accordingly, they are less prepared than larger companies to meet such severe changes in the production chain and to react with innovations. 
According to our inquiries, the companies contacted, both big and small ones, consider it necessary to adapt to the new regulations in order to stay competitive. Other than expected, however, it did not turn out to be of particular advantage to be a first mover in adapting to the new regulations in order to create new markets; rather, existing had been maintained. However, that was also a strong driver for some firms to adapt at a very early stage, even though early adaptation posed a big challenge since the detailed implementation of the regulations and the exact definition of the limit values were still in discussion. Besides, in a very early stage, suppliers were not yet able to deliver components that met the new directives, so the end product could either not be produced or was not in full compliance with the new requirements. Thus, being an early adopter does involve much more effort; e.g., the process of adaptation might require that some production processes involve the combination of lead free and plumbiferous elements. Therefore, it needs to be tested at what temperature they can be combined. Production processes have to be changed and adjusted resulting in higher costs. If regulations are not finalized these investments might turn out to be risky.

The different approaches of SMEs and large firms on new regulations are valid for both EU directives, for the WEEE and the RoHS directive. However, the effects of WEEE and RoHS on eco-innovation have to be regarded separately. One of the innovation-related purposes of WEEE is to stimulate product designers and developers to already integrate recycling options at the point of design, hence saving disposal costs in the long run. However, reality at enterprises looks different. The majority of our interview partners stated that WEEE does not have much effect on innovative design or products at their companies. In fact, innovation cycles tend to be so short nowadays that any investments into product design are not likely to anticipate cost reductions for recycling.

In most cases, feedback to the producer is not practiced because only $15 \%$ of all companies in the Austrian electronics sector are producers themselves; all others are importing from abroad. Thus, with regard to Austria, WEEE is addressing importing companies and distributors rather than original producers. Not much eco-innovation is to be expected from their side.

While WEEE regulates disposal and recycling of electronic products, RoHS starts out with the regulation of the production process. Hence, RoHS is directly addressing the manufacturing enterprises. RoHS exerts more pressure on innovation activities at the enterprise level. For example, the new limit values for lead in electronic devices require an overall transition of the soldering technology. A US company recently launched a RoHS-compliant to be used for printed circuit boards that is based on dense molecular arrangements at the nanoscale (Simmons 2005). However, neither RoHS nor WEEE is regarded as causing a revolution in the field of eco-innovation. They have been conceived on the basis of existing technologies. Moreover, the European Commission tried to phrase the directives in such a way that manufacturers would be able to easily adapt to the new requirements. Thus, radical innovations are not likely to be expected, but they are not to be excluded either. Both WEEE and RoHS has put 
some pressure on the enterprises to reflect on the way electronic products are designed as well as on their life cycle.

We do find incentives for innovation reaching beyond the product or production level. Pressure on innovation is also touching the broader organizational level: e.g. logistics, databases for components, purchase order classifications, etc. have to be changed in every company. The transition process involves the producing companies and also the partners in their network with whom they have to coordinate the changes along the value chain. Bigger and more affluent companies try to mobilize their research network, involving universities and extra-mural research organisations, in order to develop innovative products that comply with the new regulations.

The companies included in the survey stated a couple of problems and critical points caused by the transition to WEEE and RoHS. Among the most prominent are: Changes in data processing and in the entire value chain are very sumptuous and time consuming; this problem is aggravated by the fact that electronic products consist of a multitude of different components and the suppliers are located around the world. They have to comply with the new regulations, too, which involves a lot of coordination effort. Further, at least for Austria, the transition is taking place gradually, which, for example, results in hybrid forms of lead-free and plumbiferous elements complicating the production process. Finally, the long preliminary lead time before the final version of the regulations is put into practice make it difficult for companies to keep an overview on the actual status. This has resulted in a lot of confusion. Besides, during the implementation phase, a few problems occurred that had not been anticipated by the regulators. These impediments and the fact that the transition process is very time consuming and cost-intensive, especially for SMEs, might not be favourable to inducing innovations. On the contrary, this might hamper innovations, at least at the beginning of the transition process, because smaller companies have to allocate their scarce resources to the transition rather than to innovation processes.

\section{Eco directives and innovation policy - how do they fit together?}

In the Austrian case, the Austrian government decided to implement an infrastructure measure. The KERP Center of Excellence, Electronics \& Environment was initiated in 2001 to support domestic companies in the electrical, electronics, and automotive sectors in optimizing the environmental impact of their products and processes. KERP offers solutions, consulting, and research to companies in compliance with WEEE, RoHS, and a few other environmental regulations. It was initiated in order to help companies of these sectors to stay competitive on the national and international market. KERP's research unit, which released the prototype of an eco mouse, deals with the entire life cycle of products: from environmentally friendly product design through supply chain management up to recycling. KERP also offers a variety of services to individual companies, e.g., they examine the company's bills of materials, 
components' specifications, etc. with regard to best practices and compliance with RoHS. Experts in partner laboratories determine the types and quantities of substances contained in specific products. KERP also issues a certificate of all product materials complying with EU norms. This certificate provides valid proof to a company and its partners, customers, and to the authorities that all products fulfil the new standards.

Next to this function as a provider of research and service infrastructure, KERP also functions as a center of information. It organizes meetings and workshops to inform companies about the interpretation and implementation of the EU directives.

Part of its funding is provided by the Austrian Ministry of Transport, Innovation and Technology. The other part is covered by industry partners (such as ABB, Kapsch, Magna Steyr, and others). Science partners are several institutes at Austrian universities and some national as well as international research organisations.

The KERP model of innovation and environmental policy can be considered a success. The centre holds 23 co-operations with industrial partners. In this respect the center does mostly contracted research and the industry partners act as clients who pay for the product development or service. Even though there is no preference for a specific company size, it has turned out that most of the bigger electronics companies (or their Austrian subsidiaries) who were involved in the beginnings of KERP do not have a strong need for this kind of cooperation, because they are large enough to find in-house solutions. Over time, more and more small and medium sized enterprises (SME) have become the majority of partners or clients. This means that especially for the kind of companies that have the most difficulties in complying with the new EU directives a centralized information, service, and research organization seems to be a feasible solution to promote innovation on the green electronics sector. An organisation such as KERP, however, cannot serve all needs and purposes. For example, it will not move into research areas where Austrian companies are already competitive. Given it's limited financial resources, research areas that are very risky and costly cannot be covered by KERP.

Accordingly, we detect a vacuum on the level of research and innovation policy at the nexus of environmental policy. To this date no explicit policy actions have been taken to bring competencies of research organisations, SMEs, and big corporations together in order to create innovations in the green electronics sector that comply to the new environmental directives. Neither do we discern any policy efforts toward this direction in the design of Framework Programme 7 . We argue that a funding programme either on the national or European level (or both) would be suitable to create research consortia along the value chain for exchanging knowledge and ideas and for generating innovation. The impulse has to be given by a public funding programme covering parts of the costs for research projects that would be too risky to be financed by a single company.

In our further research we will explore how other research and innovation policies or environmental policies have addressed the challenge to fund research 
for innovation on the green electronics sector. We will further explore how these agenda setting processes on the national level are conducted and who the main players are. In most countries, this is a rather tedious process, as most policy makers tend to think that the implementation of the new directives is sufficient for triggering innovation in the environmental sectors. We oppose this view. Instead, our approach is that next to legal instruments, such as directives, the set of policy instruments has to be broadened, e.g. by infrastructure, information, networking, and, most of all, public funding instruments. We will give examples of countries where already existing funding programmes serve as an umbrella and allow for broadening the scope to projects addressing innovation in compliance with WEEE and RoHS, for example, in Germany or Finland.

\section{References}

[1] A.B. Smith, C.D. Jones, and E.F. Roberts, "Article Title," Journal, Publisher, Location, pp. 1-10, Date.

[2] AEA Technology, "Recovery of WEEE: Economic and Environmental Impacts" Final Report, Report for the European Commission DG XI, 1997.

[3] EC (European Commission), "Proposal for a Directive of the European Parliament and of the Council on Waste, Electrical and Electronic equipment" COM(2000) 347 final, Brussels, 2000.

[4] EBV Elektronik, "Heile grüne Welt. RoHS aus Sicht des Kundennutzens angehen" elektronik JOURNAL Österreichischer Wirtschaftsverlag $\mathrm{GmbH}, \mathrm{pp} .58-60,2005$.

[5] van Hemel, C. and J. Cramer, "Barriers and stimuli for ecodesign in SMEs", Journal of Cleaner Production, Volume 10, Issue 5, pp. 439-453, 2002.

[6] Hübner, K., J. Nill, and C. Rickert, "Greening of the Innovation System? Opportunities and Obstacles for a Path Change towards Sustainability: the Case of Germany", Diskussions papier der IÖW 47/00, Berlin, 2000.

[7] Jänicke, M., "Umweltinnovationen aus der Sicht der Policy-Analyse: vom instrumentellen zum strategischen Ansatz der Umweltpolitik", FFU-rep 97-3, 1997.

[8] Kemp, R., "Technology and Environmental Policy: Innovation Effects of Past Policies and Suggestions for Improvement", OECD Proceedings Innovation and the Environment. Sustainable Development, Paris, pp. 35$62,2000$.

[9] Lehr, U. and K. Löbbe, "Umweltinnovationen - Anreize und Hemmnisse. Ein Überblick über die innovativen umweltpolitischen Instrumente.“ Ökologisches Wirtschaften 2/1999, 1999.

[10] Rennings, K. et al., "Blueprints for an Integration of Science, Technology and Environmental Policy (BLUEPRINT)", Project financed by the 5th European Framework Programme for Research and Development, 2003. 
[11] Rennings, K., "Redefining Innovation - Eco-Innovation Research and the Contribution from Ecological Economics", Ecological Economics 32, pp. 319-332, 2000.

[12] Simmons, Ch., "Nanotechnology Innovation Solves Printed Circuit Board Failure Caused by RoHS Lead-Free Standards/CAF", SEND2PRESS NEWSWIRE, 2005.

[13] SRU - Rat von Sachverständigen für Umweltfragen, "Umweltgutachten 2002. Für eine neue Vorreiterrolle”, pp. 75ff, 2002.

[14] Tötzer, T. and B. Ömer-Rieder, "Aspects of sustainability in innovation processes: results from a business survey in the Vienna region, Austria" Conference Proceedings, 11th Annual International Sustainable Development Research Conference, 2005. 